\title{
Cyril Domb: A Personal View and Appreciation
}

\author{
Michael E. Fisher
}

Published online: 8 November 2011

(C) Springer Science+Business Media, LLC 2011

It is not given to so many scholars to found and establish an internationally influential "school" in a significant branch of Science. But that is what Cyril Domb had accomplished when, in 1981, he retired early at age 60 from King's College London to start a new life at Bar-Ilan University in Israel. His first steps on this path were taken in the Spring of 1954 when (against the advice of his Cambridge University colleagues!) Cyril Domb then 32 years old, applied for the position of Professor of Theoretical Physics at King's College London.

This Chair had been established in 1947 soon after the College returned to its original London home in Somerset House on the banks of the River Thames at the end of World War II following its evacuation to Bristol during the war. The College had been founded in 1829 by the "Establishment" as a counterblast to that "Godless hole in Gower Street," namely, University College, and, accordingly, by Statute a Faculty of Theology was to play a prominent role.

The doors of the Faculty of Natural Science opened at King's in 1831. But in those days "Theoretical Physics" was not yet the name of any accepted scientific field. Rather a position of "Professor of Natural Philosophy" was established and, in 1860, James Clerk Maxwell was so named! Indeed, as many years later Cyril Domb was to establish by his own original historical researches, it was during the subsequent years at King's that Maxwell did much of his major work. Maxwell chose to resign in 1868 and return to his Glenlair estate in Scotland before, three years later, once again moving south to become Cavendish Professor at Cambridge.

However, a Department of Physics, as such, was opened at King's in 1834, the exceptionally versatile experimentalist, Charles Wheatstone, becoming the first Professor of Physics. Later the two departments merged and distinguished scientists accepted appointments, three of whom, Charles Barkla, Owen Richardson, and Edward Appleton, later received the Nobel Prize. When the College returned to London in 1946, John Turton Randall was appointed

M.E. Fisher ( $\varangle)$

Institute for Physical Science and Technology, University of Maryland, College Park, MD 20742, USA

e-mail: xpectnil@umd.edu 
Wheatstone Professor and Head of Department. He was already well known as the inventor (with H.A. Boot) of the cavity magnetron - the crucial "heart of radar" that protected the British Isles through the War.

Randall, as Cyril Domb later noted, was a superb scientific administrator. Without a doubt he had a strong hand in appointing the first Professor of Theoretical Physics, namely, Charles Coulson internationally renowned as a theoretical quantum chemist. Indeed, Randall had decided to focus the Department increasingly on problems in Biophysics-a plan that a decade later uncovered at King's the double-helix structure of DNA through the experimental labors of Maurice Wilkins, his student Raymond Gosling and, especially, Rosalind Franklin. But at the personal level for me, as an undergraduate in Physics, Coulson was just my tutor in basic quantum mechanics. However, he was also a lay Methodist preacher and encouraged Theology students at King's. Amusement was generated in his research group by the perhaps apocryphal letter addressed to him as: "Professor of Theological Physics!"

In 1952, while I was away from King's serving for two years in the Royal Air Force, Coulson left for a Chair of Mathematics in Oxford and was succeeded by another prominent theoretical chemist, H. Christopher Longuet-Higgins. Christopher was an excellent musician and an interactive individual. It was noted by some that: "In keeping with the College's religious foundation, he is the son of a parson even if he himself has turned out to be a nonbeliever." But in only two years Longuet-Higgins moved to the Chemistry Department at Cambridge where, increasingly disenchanted by the predominant role of brute-force computation in theoretical chemistry-with little thought as he saw it—he soon shifted his interests to the workings of the brain. To that end, indeed, he eventually left Cambridge first for Edinburgh and then to Sussex.

This was the setting when, in the spring of 1954, Cyril Domb, back in Cambridge since 1952 as a Lecturer, considered the advertisement for the open Chair at London and, as he has related [1-3], looked carefully into the activities in Physics at King's and decided to apply. Another prominent, computationally oriented chemist had visited that spring and left a somewhat sour impression on members of Longuet-Higgins' group with which, as halfexperimentalist and half-theoretician [4], I was informally but closely associated. It was, thus, pleasant to learn a few months later that, likely under Randall's guiding hand, the successor to Longuet-Higgins was to be an expert in the field of Statistical Physics.

In fact, having applied, Cyril was soon short-listed and invited for interview. We now know that Cyril's first mentor from his war-time service, M.H.L. (Maurice) Pryce, was present at the interview for the Chair as an external advisor to the University of London [1-3]. Because of his previous association with Cyril he abstained from asking any questions. However, when the interviews with the four candidates were complete and the choice of the Selection Committee was clearly converging on Dr. Cyril Domb, Pryce told the King's representatives that this candidate was of Orthodox Jewish faith and would be unable to lecture or attend College functions after sundown on Fridays or on the major Jewish holidays. But the immediate response of Peter Noble, the Principal of King's College who chaired the Selection Committee was: "As long as I am Principal of this College, there will be no religious discrimination" [2]. So it was that in 1954 Cyril Domb joined King's College in time for the Michaelmas Term—named, by tradition, for the feast of St. Michael held on 29 September.

In due course when the Physics Department got to know Cyril Domb as the new Professor of Theoretical Physics, it was generally appreciated that he was of Jewish faith and, furthermore, observant. But, in distinction to Coulson's Christianity, this was never an issue that arose in the life of the College. Nevertheless, some wry observers remarked that: "This 
appointment is still in keeping with the College's religious traditions although the Authorities have now recognized that a scholar who at least respects the Old Testament is to be preferred to a nonbeliever!"

The newly minted "Professor Domb" brought many positive characteristics to King's; but an unusually sharp awareness and sensitivity to the role of "real" mathematics in applications to the physical sciences proved of prime significance. Cyril's undergraduate training in Mathematics at Pembroke College, Cambridge started in 1938, the year of the "Munich crisis" that preceded World War II. Three years later, he graduated as a "Wrangler", i.e., with First Class Honours. However, it was his war-time experiences in radar at the Admiralty Signal Establishment with the lively-minded young theorists, Hermann Bondi and Tommy Gold, under the leadership of Fred Hoyle, a few years older, that taught Cyril the power of intelligently applied mathematics for practical problems [1]. He also gained an understanding and deep appreciation for probability theory and statistics. Thus, as he has related [1, 2], on his return to Cambridge after the War in 1946, he decided on the field of Statistical Mechanics for his doctoral researches.

Soon he discovered that bringing exact mathematical methods to bear was again rewarding. From a talk by A.R. Miller at the 2V Club in Cambridge he learned of what we now invariably call "the Ising Model" and of Bethe's striking but intrinsically limited and approximate treatment [1]. Thence, for himself, Cyril discovered the transfer matrix approach and solved the one-dimensional model exactly. But, as the literature revealed, Elliott Montroll, following the pre-war work of H.A. Kramers with his postdoctoral associate G.H. Wannier, had already been there. Nevertheless, it was through Montroll's work that Cyril came to learn of Onsager's solution of the two-dimensional model in zero-field published only two years previously in 1944 .

A major outstanding question concerned the behavior of the spontaneous magnetization, $M_{0}(T)$. Cyril's first step was to recognize that the manner in which $M_{0}$ vanished as $T$ approached the critical point, $T_{c}$, entailed a nontrivial, nonobvious and, indeed unknown critical exponent, later called $\beta$. As we can now clearly see, the identification of the exponents as a central characteristic of critical behavior was, in itself, a bold and significant conceptual advance. And the suspicion that these exponents were, in later terminology "universal", over wide classes of models soon grew as Cyril Domb and Martin Sykes, his last graduate student from his three years in Oxford University, successively and reliablely estimated further basic critical exponents [5, 6].

So what approach did Cyril take to find $\beta$ for the two-dimensional Ising model? First, in terms of the variable $z=\exp \left(-2 J / k_{B} T\right)$, which vanishes when $T \rightarrow 0$, he undertook the calculation of the exact expansion coefficients of $M_{0}(T)$ to order $z^{18}$. Then in 1949 [7], from an insightful analysis of the many exact coefficients and an intelligent asymptotic extrapolation, he concluded that $\beta$ was close to or somewhat less than 0.16 . Only three years later was it seen how well this graduate student had done! Then, via a tour-de-force exact calculation by C.N. Yang - which he has described as the hardest in his career-did the exact result, namely $\beta=0.125$, become generally known!

Meanwhile, unknown to both Domb and Yang, in unpublished work described in this special issue by Rodney Baxter, Onsager himself with Bruria Kaufman, had independently found the exact expression for $M_{0}(T)$. He even announced it, in typically cryptic fashion, at a 1949 meeting in Florence to which Cyril Domb was then too junior to be invited. Nevertheless, despite early hopes — and recurring false claims [8, 9]— the three-dimensional Ising model has resisted many attempts to obtain exact results for its critical behavior. But, thanks to the pioneering insights of Cyril Domb and the developments of the theoretical techniques he launched over 60 years ago, we can now be sure that the value of $\beta$ for the Ising model 
in three spatial dimensions is close to 0.326 [10]. Furthermore, within the precision of many different studies for a variety of systems, this is also the verdict of experiment [11].

For me personally at King's in 1954, I soon benefited from the evident concern of the "new Professor" for the individual graduate students he had "inherited". As I later came to appreciate, this characteristic embodied lessons gained from his own mentors, maybe first Fred Hoyle, then as mentioned, M.H.L. Pryce, and at Oxford from 1949, a refugee from Nazi Germany but by then knighted, Sir Francis Simon, Professor of Experimental Physics. The lessons had gone to Cyril's heart where surely they had found deep intrinsic resonances.

Thus, sensing my interests in mathematics, Cyril told me of his instructive study of iterative processes for solving equations [12] stimulated by Douglas Hartree-of "Hartree-Fock" fame in quantum mechanics but also well known for his numerical works on hard problems. Cyril had noticed "degenerate iterative processes" which, in fact, solved functional equations. I found this most intriguing and was delighted to be invited to explore further [13]. In carrying the mathematics forward I learned a lot-including the power of analytic continuation which, indeed, I had never previously grasped! And, before long, Cyril also introduced me to what became my life-time affair with random walks and the beauties of generating functions [14].

Among the duties Cyril Domb naturally assumed at King's was arranging seminars for the theoretical group. His students and others enjoyed the ready access to the visitors who spoke. Indeed, I still remember vividly the visit of the third of the six students Cyril had guided to Ph.D.s in Oxford, namely Renfrey Potts, a Rhodes Scholar from Australia. Of course, he was the originator of the "Potts Model", a valuable $q$-fold extension of the Ising model devised, indeed, at the suggestion of his thesis advisor $[15,16]$ ! But when he visited King's he spoke of his work with Elliott Montroll on correlation functions for Ising models in two dimensions. Cyclic matrices appeared in quantity. And my eyes were opened when, in response to my question, he explained that cyclic matrices, however big, were always easy to diagonalize!

Cyril's concern for the welfare of the members his group was remarkable. On discovering that my supposedly prestigious University of London Postgraduate Studentship actually paid less than the standard Government grants while I already had a wife and child (and worked as a Student Librarian for the Physics Library), he made a special appeal to the College Principal for some additional support. The reply that "Mr. Fisher should have considered his situation before undertaking the responsibilities of matrimony and patrimony," brought no financial relief! But the actions on my behalf that elicited this message were surely appreciated.

Concern for the ongoing wellbeing of his theoretical "family" extended also to their future options. I was personally to benefit when the time came to address the perennial question: "But what might I do professionally once my Ph.D. thesis is accepted?" Cyril must have had doubts as to the prospects of analog computation in Britain-albeit electronic and of "ultra high speed" as my thesis work with Donald MacKay entailed [4]. Accordingly, he specifically wrote to Douglas Hartree to ask his opinion regarding what opportunities might be available in the field. The detailed reply was not encouraging: the future in the U.K. seemed to hold no promise at all. In retrospect, the aircraft industry in the United States might have provided openings for me since analog computers coupled ideally well to airplane systems. But in that era my family and I were not ready to emigrate. (Indeed, without regrets, I turned aside an approach from a mathematics section of the U.S. National Bureau of Standards - as it was then named-perhaps stimulated by a theorem on matrices I had advanced that Cyril had communicated to the Proceedings of the Cambridge Philosophical Society [17].) 
With no future in my chosen field and a family to care for, a change of direction was needed. Cyril found a fresh problem in theory for me from his contacts with Aharon Katchalsky (later Katzir), the dynamic Chair of the Polymer Division at the Weizmann Institute. This concerned the behavior of polyelectrolytes; primed with a task, I was put up for and awarded a D.S.I.R. Senior Research Fellowship. That opened a path for me in to statistical physics and, indeed, in to physical chemistry!

A similar concern for his students soon brought to London, from Oxford, Cyril's most effective and long-term collaborator, Martin F. Sykes, who, in, turn, became one of my lifetime's close friends. Martin had no evident academic ambitions of the standard genre but was deeply devoted to his researches on lattice configurations and their enumeration. His striking talents in this field provided perfect tools for deriving exactly the series expansions that under-pinned Cyril Domb's fundamental technique to extract critical exponents for so many statistical models. For Martin, during his long association with King's, Cyril arranged a title unique in the College Annals, namely: Honorary Director of Research.

Beyond his personal prowess at bringing mathematical concepts to bear on practical problems, Cyril's curiosity and his boldness in new fields, brought to his group an unceasing parade of fascinating novel problems complete with ideas on how to tackle them. With his Oxford student Hugh Barron, inspired by a polymorphic fcc-to-hcp lattice transition then recently discovered in solid helium by Dugdale and Simon, he discussed the corresponding zero-point quantum-mechanical dynamics [18]. With Dugdale he later wrote an instructive review of solid helium and its phases [19] and, more generally, of the theory of melting [20]. To this day I remember my excitement and pleasure at learning Cyril's basic argument as to why a melting line cannot end in a critical point $[19,20]$ : Simply put, a solid has long range order, a liquid does not; so while the melting transition might cease to be of first-order, it cannot cease to exist. The essence of this argument applies equally to Ising and Heisenberg lattice antiferromagnetic spin models in a magnetic field. There, indeed, a tricritical point often appears marking the transition from the analog of first-order melting to a continuous transition locus or lambda line. Years later, the same phenomenon arose in liquid helium 3-4 mixtures.

In 1958 Cyril, newly married, took seven months leave to work with Elliott Montroll in Maryland; meanwhile Martin Sykes and I collaborated fruitfully on excluded volume and related lattice problems. From that visit Cyril brought back fresh challenges: the frequency spectra of crystal lattices, the special integrals involved, and their beautiful connections to random walks [21]. In another enterprise, from John Hammersley and the statistics community, he learned of the fertile orchards of percolation problems. These gave me the pleasure of finding, with my graduate student John W. Essam, exact solutions for Bethe lattices [22]. Such "lattices" were, of course, Cyril's insightful abstraction of the sense in which Bethe's 1935 approximation - through which Cyril was first led to Ising models-could, in fact, be regarded as providing exact solutions for a special, but nontrivial, class of infinite, latticelike statistical systems. The article with Essam [22] started: "Recently Domb" has drawn attention to the problem of determining the distribution of cluster sizes for particles distributed ..."; and Footnote 1 referred to a talk by Cyril at a March 1959 Conference at Birkbeck College and a report in Nature 184, 509 (1959).

As a matter of principle, so it seemed, the "Professor" assigned quite distinct problems to the individual thesis students in his group. But he was pleased to have the members learn from one another even when, as in the work of his first graduate student at King's, John Zucker-happily, a contributor to this special issue-my personal interest led to what might be viewed as "destructive consequences." By applying Cyril's approach of taking the mathematics seriously, we discovered [23] that a seductive and bold idea for capturing the 
main consequences of strong interactions and subsequent nonlinearities in quantal ground states for crystals was totally without real merit!

But in other cases the outcomes were far happier and, needless to say, won Cyril's strong support. With the increasing availability of (digital!) computational facilities, he had suggested to Jill Bonner that she examine what might be done numerically to study Heisenberg model spin 1/2 linear chains with nearest-neighbor couplings. The initial results intrigued me and a close collaboration with Jill developed which, in fact, eventually led to one of my most-highly cited papers [24]. It also, generated a unique surprise! It should be explained that in 1963-1964 I was on leave at the Rockefeller University with Mark Kac thanks to Cyril Domb who had earlier recommended me warmly to Elliott Montroll (by then working at the IBM T.J. Watson Research Center in Yorktown Heights).

Jill and I had submitted our article to The Physical Review when, one day, there came in the mail to Rockefeller a rejection letter from a journal of which I had never heard and to which we had never sent the paper. The not too-discouraging communication was signed by Phil (P.W.) Anderson-already World famous for his many original and deep perspectives on condensed matter physics. It informed us that our work was "judged unsuitable" for his journal because it was felt to be primarily of "archival interest." So what had happened? First, Anderson was initiating an aimed-to-be-prestigious international journal titled simply "Physics." Second, Anderson had visited Cyril Domb at King's and asked what novel researches might be worthy of publication in this new venue. Ever mindful of the merits and interests of his associates, young or old, Cyril had recommended our work and, further, had given Anderson a "preprint" of our article.

My year on leave in the States with my family engendered some tempting offers and, in due course, having returned to King's, now at full professorial rank, thanks again to Cyril's support, we decided to give Cornell University a try. Thus I resigned from King's in midsummer 1966. The plan was to go for a "few years" which eventually became over 20 !

Naturally, my close scientific ties with Cyril Domb diminished over the years while I watched his group grow further in international esteem. Series expansion techniques had been taken up actively in the United States by Gene Stanley at M.I.T. and Michael Wortis and his student David Jasnow in Illinois. Distinguished visitors from overseas had been attracted to King's before I left-I recall especially George A. Baker Jr., from Los Alamos and Brookhaven, and John F. Nagle after his Ph.D. at Yale with Onsager. And others followed: Douglas Betts from Canada and, notably, from Australia, Tony Guttman, the Editor of this special issue. The visitors brought new skills and ideas to King's and in turn benefited from the stimulating research environment.

Personal honors should have been flowing to Cyril Domb in the 1960's. But, alas, since life in any field of endeavor is seldom completely just, formal recognition came unduly slowly. In 1977, thanks to the thoughtful initiative of Sam Edwards, the brilliant and versatile Cambridge theorist (who had, also, encouraged me at an early stage), Cyril was elected a Fellow of the Royal Society, news welcomed by all his colleagues, students, and admirers. In turn, Cyril was warmed by the many letters of congratulation, especially one from Sir Neville Mott, then Cavendish Professor at Cambridge, who expressed his failure to understand the delayed election. However, having signed his name in the same great Charter-Book where Isaac Newton had signed in 1671, James Clerk Maxwell in 1861, and Max Born in 1939, Cyril went on to organize a special exhibition for the 1979 Annual Conversazione of the Royal Society. This commemorated the centenary of Maxwell's death and, no doubt, the role that King's College London had played in Maxwell's own scientific life was well featured.

Also in 1979 Cyril received an Honorary Doctorate from Yeshiva University in New York City, the first academic home of Joel Lebowitz. Then the Max Born Medal for 1981 
was awarded to Cyril jointly by the German Physical Society and by the British Institute of Physics. The citation appropriately identified the pioneering researches of Cyril Domb and the school he had founded at King's College as providing the fertile soil from which grew, first, detailed scaling theories and thence, in the hands of Kenneth Wilson, the powerful renormalization group approach.

As observed above in the introductory paragraph, 1981 was also the year in which Cyril retired early from King's and moved with his family to Israel, living in Jerusalem but commuting to Bar Ilan University. There, very soon, his positive influence and his concern for colleagues and students became evident. It is good to see that articles from two of them, Shlomo Havlin and Ido Kanter, appear in this special issue.

At Bar Ilan, Cyril also took the opportunity to look back in historical breadth on the field of critical phenomena which, in many ways, had been sparked by his famous review of 1960 published in Advances in Physics [25]: the result in 1996 was his masterly book The Critical Point. The Foreword, which it was my personal pleasure to contribute [26], describes Cyril's great service to the International Statistical Physics Community in initiating with Mel Green the famous series of authoritative articles [27, 28] usually known simply as "Domb and Green." The first volume appeared in 1972. After five further volumes, very sadly, Mel Green died in Philadelphia; but Cyril then enlisted Joel Lebowitz to help carry the series through to its final close in 2001 with Vol. 20 containing a cumulative index of Authors, Titles, Subjects and Contents. On my book shelves, it now occupies over a half-a-meter filled with treasures of basic science. What a magnificent memorial for a life devoted to scholarship and deeply valued traditions!

\section{References}

1. Domb, C.: Some reminiscences about my early career. Physica A 168, 1-21 (1990)

2. Domb, C.: Reminiscences, pp. 1-204. Docostory Ltd., Raanana, Israel (2007)

3. Schweber, S.S.: An interview with Prof. Cyril Domb in Jerusalem on 10 June 2002. Available on line at: http://www.authors.library.caltech.edu/5456/1/hrst.mit.edu/hrs/renormalization/Domb/

4. Fisher, M.E.: The solution of problems in theoretical physics by electronic analogue methods. Ph.D. thesis, University of London (January 1957)

5. Domb, C., Sykes, M.F.: Use of series expansions for the Ising model susceptibility and excluded volume problem. J. Math. Phys. 2, 63-67 (1961)

6. Domb, C., Sykes, M.F.: Effect of change of spin on the critical properties of the Ising and Heisenberg models. Phys. Rev. 128, 168-173 (1962)

7. Domb, C.: Order-disorder statistics II. A two-dimensional model. Proc. Roy. Soc. A 199, 199-221 (1949)

8. Wu, F.Y., McCoy, B.M., Fisher, M.E., Chayes, L.: Comment on a recent conjectured solution of the three-dimensional Ising model. Philos. Mag. 88, 3093-3095 (2008)

9. Wu, F.Y., McCoy, B.M., Fisher, M.E., Chayes, L.: Rejoinder to the response. Philos. Mag. 88, 3103 (2008). Philos. Mag. 89, 195 (2009). Erratum

10. Pelissetto, A., Vicari, E.: Critical phenomena and renormalization-group theory. Phys. Rep. 368, 549727 (2002)

11. Sengers, J.V., Shanks, J.G.: Experimental critical-exponent values in fluids. J. Stat. Phys. 137, 857-877 (2009)

12. Domb, C.: On iterative solutions of algebraic equations. Proc. Camb. Philos. Soc. 45, 237-240 (1949)

13. Domb, C., Fisher, M.E.: On iterative processes and functional equations. Proc. Camb. Philos. Soc. 52, 652-662 (1956)

14. Domb, C., Fisher, M.E.: On random walks with restricted reversals. Proc. Camb. Philos. Soc. 54, 48-59 (1958)

15. Potts, R.B.: Some generalized order-disorder transformations. Proc. Camb. Philos. Soc. 48, 106-109 (1952)

16. Domb, C.: Configurational studies of Potts models. J. Phys. A, Math. Gen. 7, 1335-1348 (1974) 
17. Fisher, M.E., Fuller, A.T.: On the stabilization of matrices and the convergence of linear iterative processes. Proc. Camb. Philos. Soc. 54, 417-425 (1958)

18. Barron, T.H.K., Domb, C.: On the cubic and hexagonal close-packed lattices. Proc. Roy. Soc. A 227, 447-465 (1955)

19. Domb, C., Dugdale, J.S.: Solid helium. In: Gorter, C.J. (ed.) Progress in Low Temperature Physics, pp. 338-367. North-Holland, Amsterdam (1957). Chap. XI

20. Domb, C.: Some theoretical aspects of melting. Nuovo Cimento 9(1), 9-26 (1958)

21. Domb, C., Maradudin, A.A., Montroll, E.W., Weiss, G.H.: Vibration frequency spectra of disordered lattices I. Moments of the spectra for disordered linear chains. Phys. Rev. 115, 18-24 (1959)

22. Fisher, M.E., Essam, J.W.: Some cluster size and percolation problems. J. Math. Phys. 2, 609-619 (1961)

23. Fisher, M.E., Zucker, I.J.: On a non-linear differential equation for the zero-point energies of the rare gas solids. Proc. Camb. Philos. Soc. 57, 107-114 (1961)

24. Bonner, J.C., Fisher, M.E.: Linear magnetic chains with anisotropic coupling. Phys. Rev. 135, A640A658 (1964)

25. Domb, C.: On the theory of cooperative phenomena. Adv. Phys. Philos. Mag. Suppl. 9, 149-361 (1960)

26. Fisher, M.E.: Foreword: about the author and the subject. In: Domb, C., The Critical Point: A Historical Introduction to the Modern Theory of Critical Phenomena, pp. xiii-xviii. Taylor and Francis, London (1996)

27. Domb, C., Green, M.S. (eds.): Phase Transitions and Critical Phenomena, vols. 1, 2, 3, 4 (unpublished), 5A, 5B, and 6. Academic Press, London (1972-1976)

28. Domb, C., Lebowitz, J.L. (eds.): Phase Transitions and Critical Phenomena, vols. 7-20. Academic Press, London (1983-2001) 